\title{
ZnSe quantum dot based ion imprinting technology for fluorescence detecting cadmium and lead ions on a three-dimensional rotary paper-based microfluidic chip
}

\author{
Junrui Zhou ${ }^{\mathrm{a}, \mathrm{b}, 1}$, Bowei $\mathrm{Li}^{\mathrm{b}, \mathrm{d}, 1, *}$, Anjin $\mathrm{Qi}^{\mathrm{a}}{ }^{\mathrm{a}}$, Yajun $\mathrm{Shi}^{\mathrm{b}}$, Ji Qi ${ }^{\mathrm{b}}$, Huizhong $\mathrm{Xu}^{\mathrm{a}, * *}$, \\ Lingxin Chen ${ }^{\mathrm{b}, \mathrm{c}, \mathrm{e}, *}$ \\ ${ }^{a}$ School of Environment and Materials Engineering, Yantai University, Yantai, 264005, China \\ ${ }^{\mathrm{b}}$ CAS Key Laboratory of Coastal Environmental Processes and Ecological Remediation, Research Center for Coastal Environmental Engineering and Technology, Yantai \\ Institute of Coastal Zone Research, Chinese Academy of Sciences, Yantai, 264003, China \\ ${ }^{c}$ Laboratory for Marine Biology and Biotechnology, Pilot National Laboratory for Marine Science and Technology, Qingdao, 266237, China \\ ${ }^{\mathrm{d}}$ Center for Ocean Mega-Science, Chinese Academy of Sciences, Qingdao, 266071, China \\ ${ }^{\mathrm{e}}$ Department of Chemistry and Chemical Engineering, Qufu Normal University, Qufu, 273165, China
}

\section{A R T I C L E I N F O}

\section{Keywords:}

Paper-based microfluidic device

Molecularly imprinted technique

Fluorescent sensor

ZnSe quantum dots

Cadmium ions and lead ions

\begin{abstract}
A B S T R A C T
In this study, a newly fluorescent ZnSe quantum dots (QDs) with ion imprinting technology was firstly realized on the three-dimensional (3D) rotary paper-based microfluidic chip platform which can be used to realize specific and multiplexed detection of Cadmium ions $\left(\mathrm{Cd}^{2+}\right)$ and Lead ions $\left(\mathrm{Pb}^{2+}\right)$. Compared to CdTe quantum dots, ZnSe quantum dots are less toxic and more environmental friendly. In addition, this design improved the portability of the device by transferred the liquid phase of ZnSe QDs@ion imprinted polymers to solid glass fiber paper. Moreover, the 3D rotary microfluidic chip ( $\mu$ PADs) showed great advantages including low cost, simple and fast facile operation, multiplexed detection, and showed good sensitivity and selectivity. Under optimal experiment conditions, our proposed method was enabled to realize specific and multi-channel determination of $\mathrm{Cd}^{2+}$ and $\mathrm{Pb}^{2+}$ ions. The developed sensor of $\mathrm{Cd}^{2+} \mu$ PADs provided a linear response from 1 to $70 \mu \mathrm{g} / \mathrm{L}$ with a lower detection limit of $0.245 \mu \mathrm{g} / \mathrm{L}$, and $\mathrm{Pb}^{2+} \mu \mathrm{PADs}$ provided a linear response from 1 to $60 \mu \mathrm{g} / \mathrm{L}$ with a lower detection limit of $0.335 \mu \mathrm{g} / \mathrm{L}$, respectively. Excitingly, this newly designed 3D rotary $\mu$ PADs exhibited quantitative information conveniently, which showed the promising application prospects to rapid testing target metal ions in environmental in the future.
\end{abstract}

\section{Introduction}

Heavy metal ion pollutions have caused a number of serious threats, even if they were low in concentration, and they were also very toxic and pose high risks to the environment and human health [1,2]. Cadmium (Cd) element is a non-essential element of the human body. It is generally low in nature and does not affect human health under normal environmental conditions. When the environment is contaminated by cadmium, cadmium can be enriched in the organism, causing chronic poisoning of the human body through the food chain. Among them, the kidney can absorb nearly one-third of the cadmium in the body, which is the "target organ" of cadmium poisoning $[3,4]$. At the same time,
Lead $(\mathrm{Pb})$ is a toxic heavy metal, which is not degradable in the environment and potentially toxic to many living tissues. Lead pollution will cause children grow slowly or developmentally delayed, and even leading to death [5]. According to the maximum level of drinking water standards of United States Environmental Protection Agency issued, the content of cadmium and lead ions are lower than $5 \mu \mathrm{g} / \mathrm{Land} 15 \mu \mathrm{g} / \mathrm{L}$, respectively. Therefore, microanalysis of cadmium ion $\left(\mathrm{Cd}^{2+}\right)$ and lead ion $\left(\mathrm{Pb}^{2+}\right)$ in water environment monitoring has become the focus of human attention. Many methods can be used for the determination of $\mathrm{Cd}^{2+}$ and $\mathrm{Pb}^{2+}$ ions in complicated water environments, such as colorimetric sensors [6-8], electrochemical analysis [9-11], fluorescent sensors [12-14], Raman scattering sensors [15], etc.

\footnotetext{
* Corresponding authors at: CAS Key Laboratory of Coastal Environmental Processes and Ecological Remediation, Research Center for Coastal Environmental Engineering and Technology, Yantai Institute of Coastal Zone Research, Chinese Academy of Sciences, Yantai, 264003, China.

** Corresponding author.

E-mail addresses: bwli@yic.ac.cn (B. Li), ytdxxhz@126.com (H. Xu), lxchen@yic.ac.cn (L. Chen).

${ }^{1}$ Junrui Zhou and Bowei Li contributed equally to this work.
} 
With the development of miniaturization and integration, 3D microfluidic paper-based analytical devices ( $\mu$ PADs) have received widespread attentions [16-19], which showed great advantages in environmental analysis [20]. It had the advantages of low cost, portability and quick detection in the field [21,22]. The main materials of microfluidic chip are glass, silicon wafer, paper, etc. Compared with the materials of silicon wafer and glass, the cost of paper chip is very low, and easy to fabricate. And its operation is simple, without external drive pump, and just relies on the paper's capillary force to realize liquid's flowing. In addition, the paper is small, easy to carry and transport, and the paper can be burned that is environmental user-friendly. After combined with a variety of detection methods simultaneously, such as fluorescence [23,24], electrochemical [25-27], surface enhanced Raman spectroscopy [28,29], and colorimetric detection [30,31], it can be used in a wide range of chemical analysis areas.

Quantum dots (QDs) had high fluorescence yield, high stability and good luminescence performance, hence they were widely used in environmental monitoring, food safety testing, and biomedical field since recent years [32-34]. For instance, Xu et al. detected streptomycin based on CdTe QDs [35]. Wang et al. assembled a high-sensitive electrochemical sensor of Sudan I based on ZnSe QDs [36].Wang et al. established a bright, efficient, and color-stable violet light-emitting diodes based on ZnSe QDs [37]. In this work, ZnSe QDs was chosen to take place of the previous cadmium series of QDs, because the QDs of the cadmium series are biologically toxic, and they will cause environmental pollution and damage human health if they are handled improperly. On the contrary, ZnSe QDs are almost no toxicity, and will not cause pollution damage to the environment and human body [38]. Moreover, the synthesis method is simple, and the quantum dot yield is high and stable. It is well known that there are many substances that can quench the fluorescence of QDs. Using this principle, we combined ion-imprinting technology with QDs to produce a fluorescence sensor with high sensitivity and high selectivity $[39,40]$. The development of ion imprinting technology is based on molecular imprinting technology [41-43]. In this experiment, we presented an attempt at preparation of ion imprinted polymers on the glass fiber paper using $\mathrm{Cd}^{2+}$ or $\mathrm{Pb}^{2+}$ ions as the templates, and then crosslinked the functional monomer APTES by chelation reaction under the influence of TEOS. Finally, the template ions are eluted by the acidic solution to remove the template ions and produce the caves in the imprinted polymer layers, and these caves are matched with the template ions, so that the specific recognition of the template ions can be realized $[44,45]$. Vatanpour et al. developed an ion imprinted membrane based on ion imprinting technology to detect nickel ion [46]. Qi et al. assembled a origami $\mu$ PADs based on ion imprinting technology to measure $\mathrm{Cu}^{2+}$ and $\mathrm{Hg}^{2+}$ ions [47].

In this work, we firstly used ZnSe QDs wrapped with ion imprinted polymers on 3D rotary $\mu$ PADs for the detection of $\mathrm{Cd}^{2+}$ and $\mathrm{Pb}^{2+}$ ions. The 3D $\mu$ PADs not only can realize multiplexed detection, but also could be compatible of implementing pretreatment for the different water. The biologically toxic CdTe QDs were replaced by ZnSe QDs, which greatly improved the safety performance and ensured the recognition ability of ions. According to our investigation, this is the first time to combine ion imprinting technology and ZnSe QDs on 3D rotary $\mu$ PADs platform to realize the determination of $\mathrm{Cd}^{2+}$ and $\mathrm{Pb}^{2+}$ ions. In addition, the proposed method provided a simple, facile and robust method to detect other metal ions using appropriate template ions.

\section{Experimental section}

\subsection{Materials}

Selenium (Se), zinc acetate dehydrate $\left(\mathrm{Zn}\left(\mathrm{OAC}_{2}\right) \cdot 2 \mathrm{H}_{2} \mathrm{O}\right)$, sodium borohydride $\left(\mathrm{NaBH}_{4}\right), 3$-aminopropyltriethoxysilane (APTES), N-hydroxysuccinimide (NHS) and 3-ethylcarbodiimide hydrochloride (EDC) were bought from Aladdin Bio-chem Technology Co.LTD
(Shanghai,China). 2- $N$-morpholinoethanesulfonic acid (MES) were procured from Sigma-Aldrich (Shanghai,China). thioglycollic acid (TGA), ethanol, ammonia solution $\left(\mathrm{NH}_{3} \cdot \mathrm{H}_{2} \mathrm{O}\right)$, tetraethoxysilane (TEOS), $\mathrm{NaOH}, \mathrm{HCl}$ and other reagents were procured from Sinopharm Chemical Reagent Co.LTD (Shanghai, China). Whatman No.1 chromatography paper was acquired from GE Company (Shanghai, China). Glass fiber paper was purchased from blue sky environmental monitoring products factory (Shandong Dezhou, China). All aqueous solutions used were ultrapure water (18.2 M $\Omega$ specific resistance), which was obtained from a Cascada laboratory water system (Millipore, Bedford, MA, USA).

\subsection{Instruments}

Adobe Illustrator (drawing software) was used to design pattern, To form a hydrophobic channel, the wax was printed on the Whatman No.1 chromatography paper by XEROX Phaser 8560DN, and then kept in an bake oven at $120^{\circ} \mathrm{C}$ for $30 \mathrm{~s}$. Fluorescence spectrum was obtained by a spectrofluometer (Fluoromax-4, HORIBA): the excitation wavelength of the $\mathrm{ZnSe}$ QDs was $348 \mathrm{~nm}$, and the emission spectrum between the wavelengths of $360 \sim 430 \mathrm{~nm}$ was recorded. Scanning microscope(SEM; JSM $5600 \mathrm{~L} \mathrm{~V}$ ) was used to show the morphology of the chip. Preparation process was determined by detecting the infrared spectrum with Fourier transform infrared spectrometer (Nicolet iS10, Thermo Scientific).

\subsection{Synthesis of water-soluble TGA-modified ZnSe QDs}

The synthesis of water-soluble TGA-modified ZnSe QDs was mainly based on the previously literature [48]. For the synthesis of zinc precursor, $100 \mathrm{ml}$ of $\mathrm{Zn}(\mathrm{OAc})_{2}$ solution $(0.5 \mathrm{mM})$ and $1.5 \mathrm{mM}$ of TGA were dissolved in a three-hole flask, and the reaction media was adjust to $\mathrm{pH}$ 9.5 with $1.0 \mathrm{M}$ of $\mathrm{NaOH}$ and bubbled with $\mathrm{N}_{2}$ to maintain an anaerobic environment. At the same time, $4.8 \mathrm{mg}$ of Se and $18.9 \mathrm{mg}$ of $\mathrm{NaHB}_{4}$ were dissolved in $5 \mathrm{ml}$ of icy ultrapure in a centrifuge tube, and then the reaction was carried out in an ice water bath at a temperature of 2 to $4^{\circ} \mathrm{C}$ for $1 \mathrm{~h}$ to format NaHSe solution. At this point, all the Se disappeared and a small amount of white crystal appeared at the bottom of the bottle. Next, after injecting freshly prepared of NaHSe solution into the three-hole flask and the whole system was stirred and heated to boiling for $2 \mathrm{~h}$. When the solution was naturally cooled to room temperature, the solution was irradiated by a $6 \mathrm{~W}$ UV lamp with a wavelength of $245 \mathrm{~nm}$ for $18 \mathrm{~h}$. The synthetic of TGA-modified ZnSe QDs showed excellent blue-green fluorescence at $370 \sim 400 \mathrm{~nm}$.

\subsection{Synthesis of glass fiber paper (paper@ZnSe QDs) based fluorescent sensors}

The glass fiber paper's dimension was $9 \times 9 \mathrm{~mm}$. After immersed in $0.2 \mathrm{M} \mathrm{HCl}$ solutions for $30 \mathrm{~min}$, it was rinsed two times by ultrapure water to get rid of extra hydrochloric acid. Subsequently, we mixed $150 \mu \mathrm{L}$ of APTES and $20 \mathrm{~mL}$ ethanol solution (50\%), and the glass fiber paper was immersed in the mixture and oscillated for $2 \mathrm{~h}$ to graft amino groups, and then rinsed twice with ultrapure water to remove unreacted residual. $10 \mathrm{~mL} \mathrm{ZnSe}$ QDs, $6 \mathrm{~mL}$ of NHS $(10 \mathrm{mg} / \mathrm{mL})$ and $6 \mathrm{~mL}$ of EDC $(20 \mathrm{mg} / \mathrm{mL})$ solutions were added in order. After reacted by oscillation in the dark for $3 \mathrm{~h}$, ZnSe quantum dots were grafted on the glass fiber paper. In the experiment, covalent bonds on the paper@ZnSe QDs to ensure the ZnSe QDs could be grafted firmly, and kept the signal high and stable.

\subsection{Synthesis of ion imprinted polymers on glass fiber paper (paper@ZnSe QDs@IIPs)}

The fabricated paper@ZnSe QDs@IIPs (PQ-IIP) was prepared by reported literatures $[49,50]$. In order to form PQ-IIP of $\mathrm{Cd}^{2+}$ ion, $75 \mu \mathrm{L}$ 
of APTES (functional monomer) and $5 \mathrm{~mL}$ of $10 \mathrm{mg} / \mathrm{L} \mathrm{Cd}^{2+}$ ion were mixed in the beaker for $10 \mathrm{~min}$. under continuous oscillation with $150 \mathrm{rpm}$, followed by addition of $70 \mu \mathrm{L}$ of $\mathrm{NH}_{3} \cdot \mathrm{H}_{2} \mathrm{O}$ (initiator) and $70 \mu \mathrm{L}$ of TEOS (cross linker) reagents, and the oscillation was adjusted to 120 rpm. When the mixture was turned into white turbid, paper@ZnSe QDs were added and kept the oscillation for $5 \mathrm{~h}$ in the dark to generate the ion imprinted polymer. The PQ-IIP of $\mathrm{Pb}^{2+}$ ion was synthesized in the same way by using $\mathrm{Pb}^{2+}$ template ion. $0.01 \mathrm{mM}$ of EDTA solution was used as $\mathrm{Cd}^{2+}$ and $\mathrm{Pb}^{2+}$ ions elution reagent. In control experiment, we guaranteed the same experimental conditions but except adding $\mathrm{Cd}^{2+}$ and $\mathrm{Pb}^{2+}$ template ions, and named it non-imprinted polymers paper@ZnSe QDs-NIP(PQ-NIP).

\subsection{Preparation of $3 D$ rotary $\mu P A D s$}

The 3D PQ-IIP $\mu$ PADs device was designed by Freehand MX software. As shown in Fig. S1, after printing on the Whatman No.1 chromatography paper by printer XEROX Phaser 8560DN, the $\mu$ PADs was baked in an oven at $120^{\circ} \mathrm{C}$ for $30 \mathrm{~s}$ to form a hydrophobic structure.

Fig. S2 contained all the component parts to assembly the 3D rotary $\mu$ PADs. As displayed the figure, the $\mu$ PADs was consisted with three layers, including top circular sampling layer (red color), middle rectangular isolation layer (yellow color), and bottom rectangular sensor layer (green color). The diameter of the top sampling layer was $55 \mathrm{~mm}$, including two sample introducing areas, four sample transporting areas, two hydrophilic channels, and two detecting windows $(9 \mathrm{~mm} \times 9 \mathrm{~mm})$. The side length of the middle rectangular isolation layer was $55 \mathrm{~mm}$, including four rectangular holes $(9 \mathrm{~mm} \times 9 \mathrm{~mm})$, corresponded to the bottom sensing sites. The function of the middle layer acted as a barrier to prevent the sample on the top layer to leak and contaminate the bottom layer. The side length of the bottom rectangular sensor layer was the same size as the middle layer, including four rectangular $(9 \mathrm{~mm} \times 9 \mathrm{~mm})$ fluorescent components (PQ-IIP components).

\section{Results and discussions}

\subsection{Preparation of paper@ZnSe QDs@IIPs component}

In this work, the glass fiber paper was used as substrate to manufacture $\mu$ PADs, because the surface of $\mu \mathrm{PADs}$ is $\mathrm{SiO}_{2}$ that is beneficial to let the ZnSe QDs graft firmly. To prove it, paper@ZnSe QDs were rinsed three times with ultrapure water and measured its fluorescence intensity, then it was used to make a comparison with the fluorescence intensity before rinsing. As illustrated in Fig. S3, the fluorescence intensity of the ZnSe QDs grafting onto the glass fiber paper by covalently immobilization (Curve a) was much stronger than the physical adsorption (Curve c) grafting. Meanwhile, the fluorescence intensity of paper@ZnSe QDs almost showed no change after rinsing three times with ultrapure water (Curve b). This phenomenon indicated that the ZnSe QDs attached to the glass fiber paper firmly under the action of covalent bonds and had the good ability to keep the signal stable. From the FT-IR spectra of bare paper, paper@ZnSe QDs and paper@ZnSe QDs in Fig. S4, it could indicate that ZnSe QDs and ion imprinted polymers were successfully grafted.

The sensing principle and the process of ion imprinted polymers grafted to the glass fiber paper were displayed in Fig. 1. For covalent linking to the glass fiber paper, the bare paper was first soaked in $\mathrm{HCl}$ solutions for $30 \mathrm{~min}$ to make the $\mathrm{OH}^{-}$groups activated and to remove impurities. $150 \mu \mathrm{L}$ APTES was added, which interacted with glass fiber paper to graft amino groups on it. With the action of $6 \mathrm{~mL}$ of EDC $(20 \mathrm{mg} / \mathrm{L})$ and $6 \mathrm{~mL}$ of NHS $(10 \mathrm{mg} / \mathrm{L})$, the glass fiber paper's amino groups and ZnSe QDs's carboxyl groups reacted to form an amide bond, and the QDs can be grafted on the glass fiber paper firmly. To form ion imprinted polymers, template $\mathrm{Cd}^{2+}$ (or $\mathrm{Pb}^{2+}$ ) ion solution and $80 \mu \mathrm{L}$ APTES (functional monomer) were added to the beaker for $10 \mathrm{~min}$. under continuous oscillation with $150 \mathrm{rpm}$, then $75 \mu \mathrm{L}$ TEOS (cross-

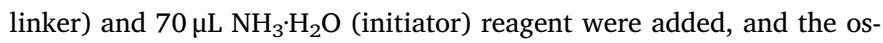
cillation was adjusted to $120 \mathrm{rpm}$. When the mixture turned into white turbid, the paper@ZnSe QDs were immersed into the polymerization solution and kept the oscillation for $5 \mathrm{~h}$ in the dark to get paper@ZnSe QDs@Cd ${ }^{2+}$-IIPs(PQ-Cd-IIP) or paper@ZnSe QDs@ $\mathrm{Pb}^{2+}$-IIPs(PQ-PbIIP). When the template ions were existed, the fluorescence of the QDs was quenched. The fluorescence intensity signal of the QDs was recovered after eluting the template ions, as shown in Fig. 1.

\subsection{Characterization of paper@ZnSe QDs@IIPs component}

In this work, glass fiber paper was used to assemble onto 3D microfluidic paper chips to fabricate a facile, rapid and simple detection for $\mathrm{Cd}^{2+}$ and $\mathrm{Pb}^{2+}$ ions. The morphologic structures of the modified paper were characterized by SEM. From the SEM images in Fig. 2A and $\mathrm{B}$, an irregular clear dendritic fiber structure of the bare glass fiber paper can be observed. In the case of the amide bonding reaction, the glass fiber paper was covered by a large number of quantum dots. In addition, it was discovered by observation under a high-power SEM that there were obvious protrusions on the surface of the glass fiber paper, indicated that the quantum dots were distributed uniformly (shown in Fig. 2C and D). Fig. 2E and F showed ion imprinted polymers were synthesized successfully, it could be seen that the surface of quantum dots were wrapped with spherical imprinted polymers and coated on the fiber simultaneously, and its diameter was about $250 \mathrm{~nm}$.

\subsection{Assembly and operation of paper@ZnSe QDs@IIPs $\mu$ PADs}

The newly designed PQ-IIP $\mu$ PADs had advantages such as easy portability, multiplexed detection, high selectivity and sensitivity for detecting two sets of $\mathrm{Cd}^{2+}$ and $\mathrm{Pb}^{2+}$ ions by $\mu$ PADs. The entire manipulation inspection process was shown in Fig. 3A-F. During the process of assembly, the top sampling layer was combined with middle layer. Then, we assembled the top layer, middle isolation layer and the bottom sensor layer, ensuring that the sample area of the top layer corresponds to the holes of the middle layer and sensing sites of the bottom layer. In addition, to ensure that the top layer can be rotated freely, these three layers are fixed together using a hollow rivet. By rotating the top layer, the bottom sensor site was exposed and could be directly detected by the fluorescent device. These $\mu$ PADs not only guaranteed the efficiency of detection, but also facilitated the convenience of detection. During the detection, $30 \mu \mathrm{L}$ samples were added to the injection sample introducing area (Fig. 3C), and liquid flowed through the hydrophilic channels to the sample detection areas. Subsequently, the samples reacted with the PQ-IIP components on the bottom layer and its fluorescence intensity would be decreased due to the quenching effect. After the reaction completed, we rotated the top and middle layer to let PQ-IIP components on the bottom layer exposed and the $\mu$ PADs were placed on the shelf of the Fluoromax- 4 spectrofluometer to test the fluorescence signals (Fig. 3E). Fig. 3F showed the photograph of the fluorescence of PQ-IIP $\mu$ PADs under the UV light.

\subsection{Sensing principle of paper@ZnSe QDs@IIPs $\mu$ PADs}

Sensing material of ZnSe QDs was firstly used to test $\mathrm{Cd}^{2+}$ and $\mathrm{Pb}^{2+}$ ions on PQ-IIP $\mu$ PADs. The sensing principle of the quenching may involve electronic transfer from the QDs to the relative ions due to the formation of the Meisenheimer complex that was produced between ions and primary amino groups of QDs surface. Mainly, when the target $\left(\mathrm{Pb}^{2+}\right.$ or $\mathrm{Cd}^{2+}$ ions) was present, a Meisenheimer complex would be formed between primary amino groups of QDs surface and target ions, and then the photoluminescent energy of QDs would be transferred to the complex, resulting in the fluorescence quenching of QDs. Therefore, the contents of the $\mathrm{Cd}^{2+}$ and $\mathrm{Pb}^{2+}$ ions could be detected by particular recognition sites of ion imprinted polymers on the fiber paper surface. The fluorescence quenching effect in our experiment followed the 


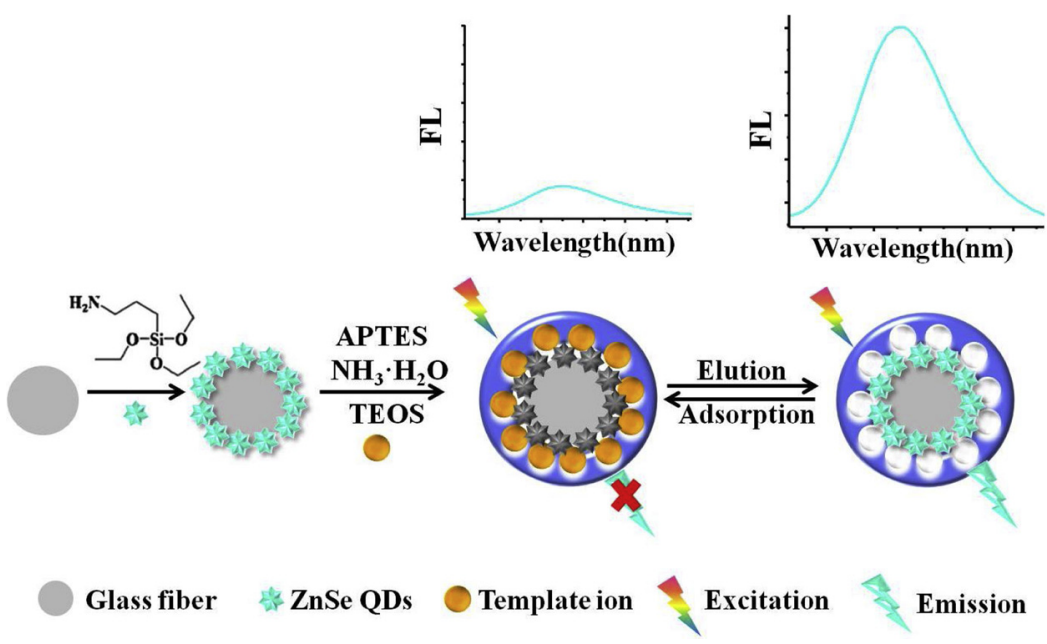

Fig. 1. Schematic illustration of the sensing principle and imprinting process of ion imprinted polymers of the rotary Microfluidic Chip.
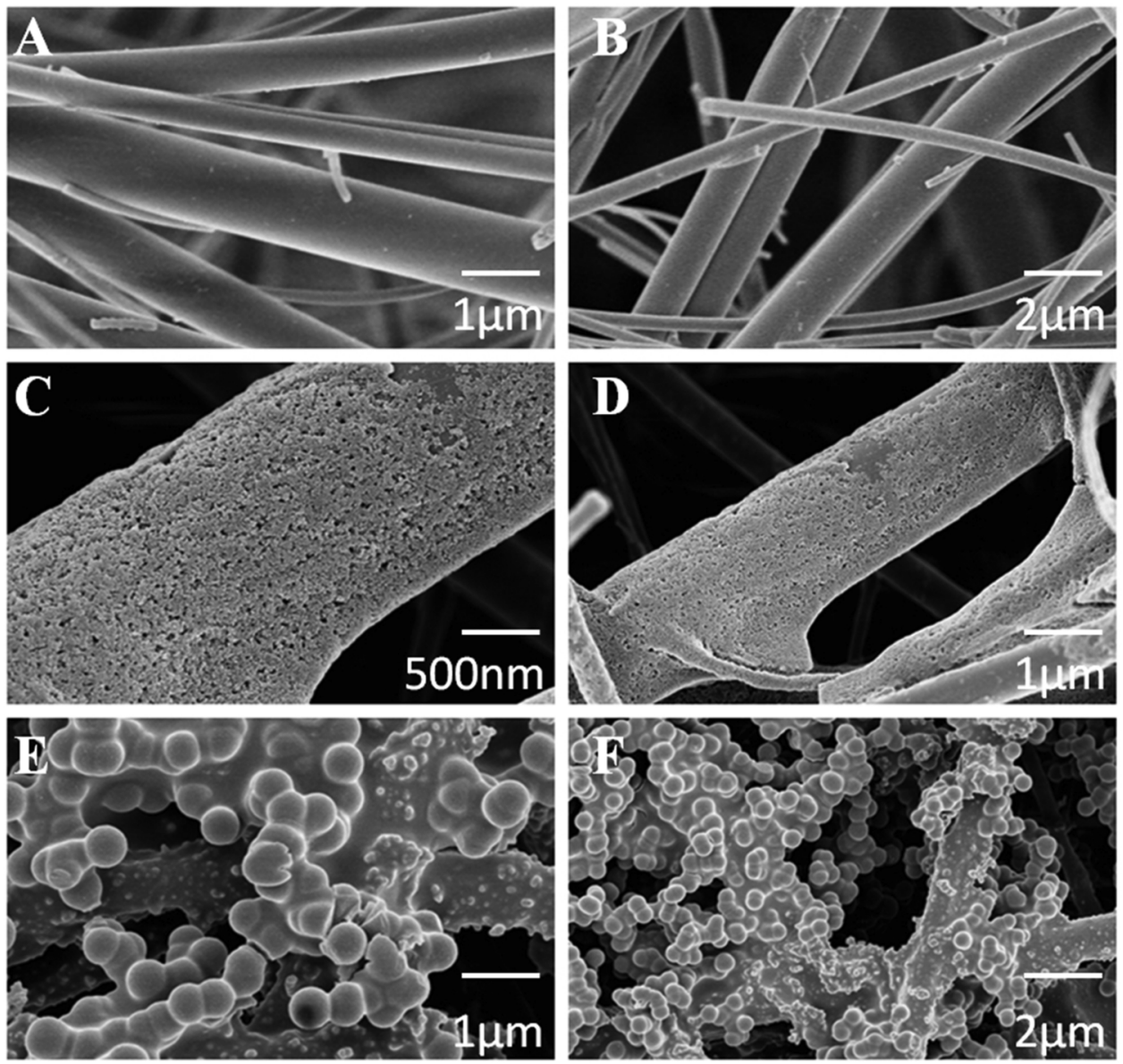

Fig. 2. SEM images of the paper@ZnSeQDs@IIPs: (A)(B) bare glass fiber paper; (C) (D) paper@ZnSe QDs; (E)(F) paper@ZnSeQDs@IIPs.

Stern-Volmer equation:

$\left(F_{0} / F\right)-1=K_{\mathrm{SV}} C_{\mathrm{M}}$

Where $\mathrm{F}_{0}$ and $\mathrm{F}$ are the fluorescence intensities of the chips in the absence of template ions and the presence of template ions, respectively. $K_{\mathrm{SV}}$ represents the quenching constant, $C_{\mathrm{M}}$ is the consistence of the template ions. This formula is applied to quantify the different quenching constants in this study, and assess the selectivity of the ion imprinted by the imprinting factor (IF). It was defined by the ratio of the $K_{\mathrm{SV}}$ values of imprinting chip and non-imprinting chip ( $K_{\mathrm{SV}}$, IIP/
$\left.K_{\mathrm{SV}}, \mathrm{NIP}\right)$.

3.5. Optimization of experimental conditions of paper@ZnSe QDs@IIPs $\mu P A D s$

The fluorescence intensity and stability of the PQ-IIP $\mu$ PADs depend to a large extent on certain variables, such as equilibrium time, elution time, $\mathrm{pH}$. Under optimized experimental conditions, the stability and sensitivity of the $\mu$ PADs will be greatly improved. Therefore, it is extremely important to optimize the experimental conditions. 

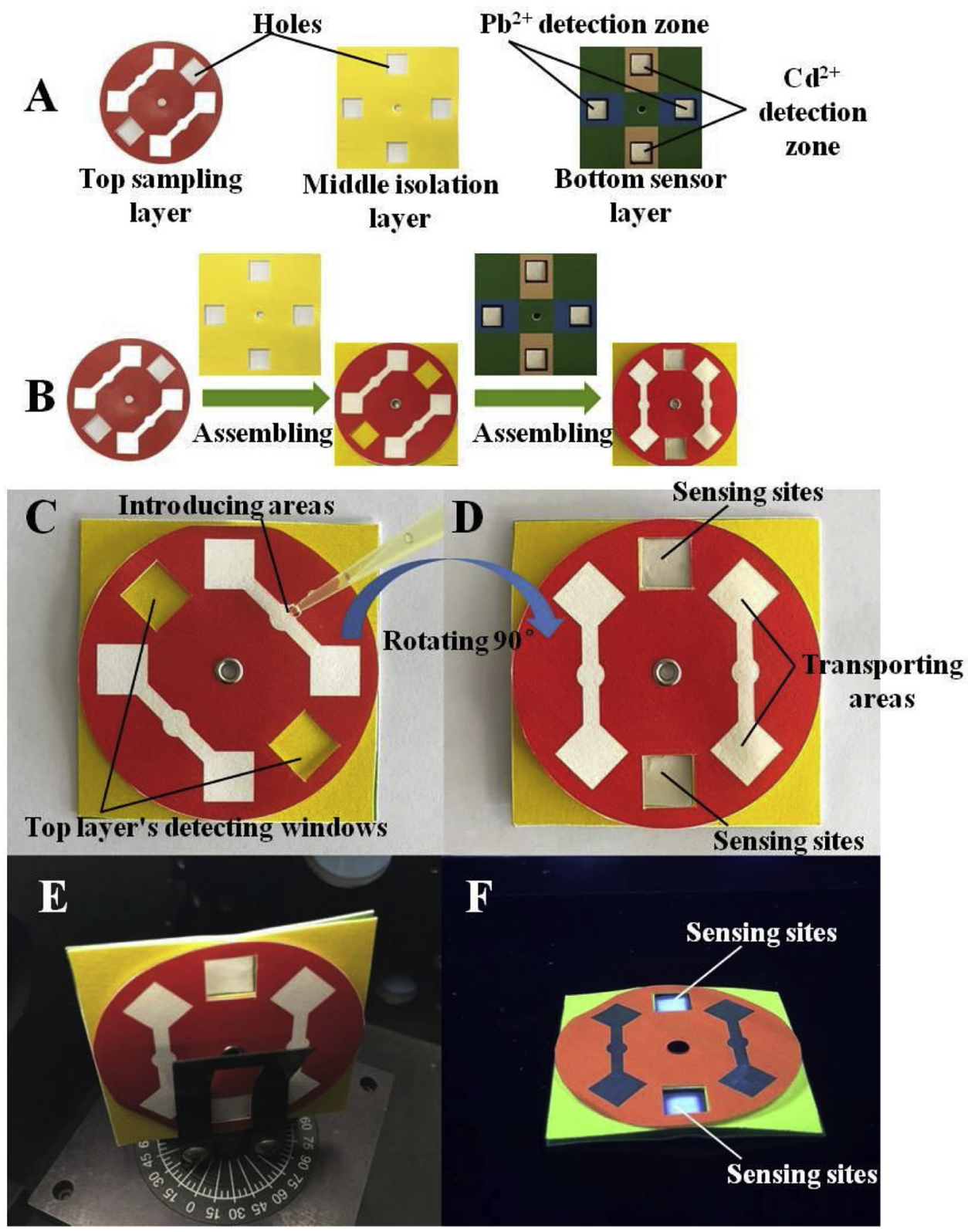

Fig. 3. The entire assembly and detection process of ion imprinting paper-based chip. (A) Three layer's paper-based chip and its components, (B) chip's assembling process, (C) adding samples to the introducing area, (D) rotating the top layer $90^{\circ}$ to facilitate the detecting windows on the top layer corresponded to the paper@ ZnSe QDs@IIPs sensing sites of the bottom layer, (E) putting the paper@ZnSe QDs@IIPs $\mu$ PADs on the shelf of the Fluoromax-4 spectrofluometer to test the fluorescence signals, (F) photo of paper@ZnSe QDs@IIPs $\mu$ PADs under the UV light.

The $\mathrm{pH}$ of the solution affected the ability to recognize $\mathrm{Cd}^{2+}$ and $\mathrm{Pb}^{2+}$ ions, thereby further affected the fluorescence stability and intensity of the PQ-IIP $\mu$ PADs. Therefore, the effect influence of $\mathrm{pH}$ on fluorescence intensity was investigated within the $\mathrm{pH}$ range of $5.0 \sim 8.5$. As seen from Fig. $4 \mathrm{~A}$, when the $\mathrm{pH}$ value was between $5.0 \sim 5.5$, the fluorescence intensity was extremely weaker than others. When the $\mathrm{pH}$ value was around $5.5 \sim 7.0$, the fluorescence intensity enhanced greatly, and the fluorescence intensity attained a maximum at the $\mathrm{pH}$ of 7.0. As the $\mathrm{pH}$ value continued to increase, the fluorescence intensity reduced rapidly at the $\mathrm{pH}$ value between $7.0 \sim 8.5$, because the interaction sites among the ion imprinted shell binding recognition sites and the target $\mathrm{Cd}^{2+}$ and $\mathrm{Pb}^{2+}$ ions were de-protonated, caused a dramatic decline of the fluorescence signal. Because the optimized $\mathrm{pH}$ value is 7 , and considering that the actual water sample's $\mathrm{pH}$ value is 7 , we don't need to adjust it with a buffer solution.

In order to investigate the adsorption equilibrium time of the ion imprinted polymers with template $\mathrm{Cd}^{2+}$ and $\mathrm{Pb}^{2+}$ ions, an equilibrium adsorption analysis was carried out, and the concentration of the $\mathrm{Cd}^{2+}$ and $\mathrm{Pb}^{2+}$ ions were $30 \mu \mathrm{g} / \mathrm{L}$ in this experiment. Kinetic profiles of the imprinted polymers with template ions were determined using direct fluorescence detection, as described in Fig. 4B. The fluorescence intensity decreased obviously from $0 \sim 10 \mathrm{~min}$. During $10 \mathrm{~min}-14 \mathrm{~min}$, the rate of fluorescence decline begins to slow and reached a plateau at $15 \mathrm{~min}$. Hereafter, the fluorescence intensity gradually stabilize because the recognition sites of the ion imprinted polymers were fully combined with $\mathrm{Cd}^{2+}$ or $\mathrm{Pb}^{2+}$ ions. Therefore, 15 min was selected as the optimal time.

In the process of synthesizing ion imprinted polymers, an appropriate amount of functional monomer is beneficial to the polymers to have better recognition ability and adsorption characteristics. In order to prevent self-polymerizing of APTES to form more non-specific biding sites that would decrease of the components adsorption performance, 

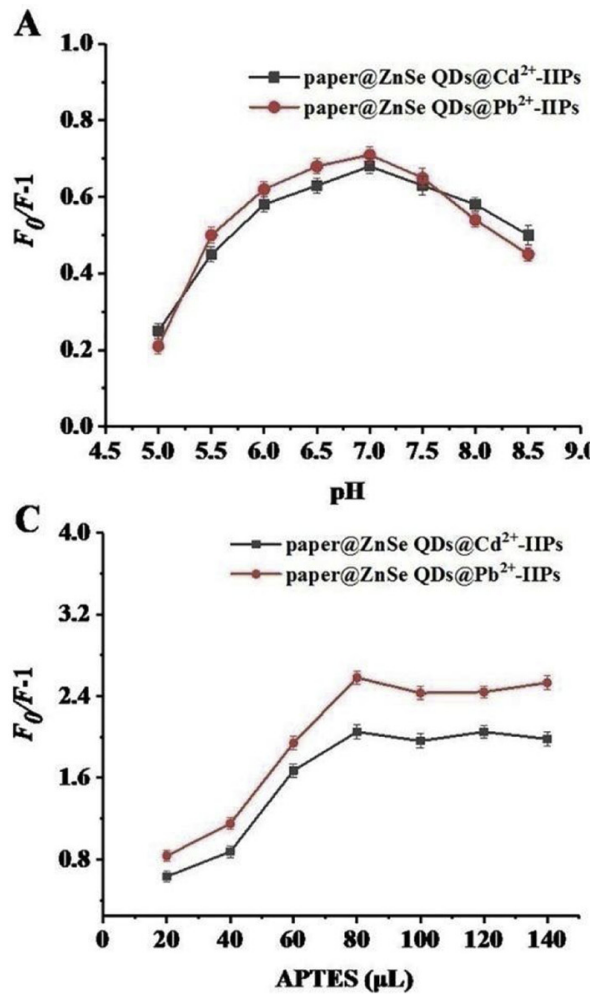
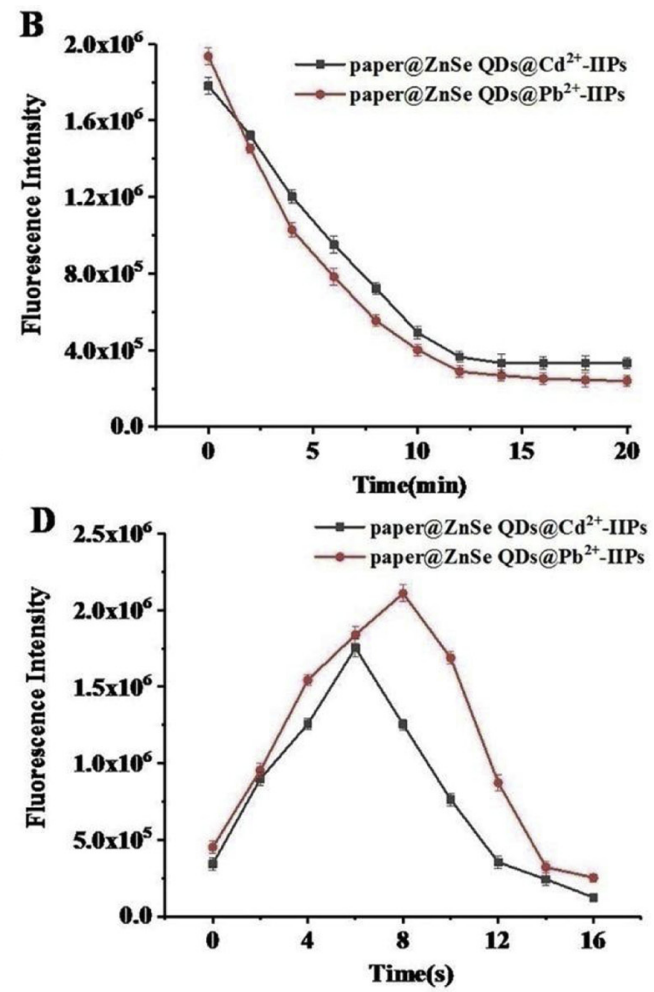

Fig. 4. (A) Effect of $\mathrm{pH}$ on fluorescence quenching effect of paper@ZnSe QDs@Cd ${ }^{2+}$. IIPs and paper@ZnSe QDs@Pb ${ }^{2+}$-IIPs, (B) The fluorescence intensity changes of paper@ZnSe QDs@Cd ${ }^{2+}$-IIPs and paper@ZnSe QDs@ $\mathrm{Pb}^{2+}$. IIPs during $20 \mathrm{~min}$, (C) Effect of the amount of APTES on fluorescence quenching effect of paper@ZnSe QDs@Cd ${ }^{2+}$-IIPs and paper@ZnSe QDs@ $\mathrm{Pb}^{2+}$-IIPs, (D) Effect of elution time on fluorescence intensity changes of paper@ZnSe QDs@Cd ${ }^{2+}$-IIPs and paper@QDs@ $\mathrm{Pb}^{2+}$-IIPs. the amount of functional monomer APTES was investigated. It can be seen from the Fig. 3C, in the range of $20 \mu \mathrm{L}$ to $80 \mu \mathrm{L}$, the fluorescence intensity of the PQ-Cd-IIP declined with the increase of APTES, and reached a plateau at $80 \mu \mathrm{L}$. In the range of $80 \mu \mathrm{L} \sim 140 \mu \mathrm{L}$, the fluorescence intensity of the PQ-Cd-IIP almost no changed, indicating that the amount of functional monomer APTES was enough. As illustrated in Fig. 3C, the fluorescence intensity trend of the PQ-Pb-IIP almost the same as the PQ-Cd-IIP with the increase of APTES. Therefore, the amount of APTES was selected as $80 \mu \mathrm{L}$.

Due to the method of surface imprinting, EDTA solution could elute the template $\mathrm{Cd}^{2+}$ and $\mathrm{Pb}^{2+}$ ions in a very short time. But if the elution time was too long or the concentration of EDTA was too high, it also had a quenching effect on the fluorescence. According to previous reports [47], $0.01 \mathrm{mM}$ of EDTA solution was selected as the elution reagent, so we investigated the elution time of EDTA solution. As shown in Fig. 4D, between $0 \sim 6 \mathrm{~s}$, the fluorescence intensity of the PQ-Cd-IIP was increased, and reached maximum at $6 \mathrm{~s}$, then the fluorescence intensity of the PQ-Cd-IIP began to decrease, so we determined the optimal elution time as $6 \mathrm{~s}$. Similarly, the fluorescence intensity of the PQ$\mathrm{Pb}-\mathrm{IIP}$ was reached maximum at $8 \mathrm{~s}$, so the optimal elution time was selected as $8 \mathrm{~s}$.

\subsection{Detecting of $\mathrm{Cd}^{2+}$ and $\mathrm{Pb}^{2+}$ ions on paper@ZnSe QDs@IIPs $\mu$ PADs}

The quantitative detection of $\mathrm{Cd}^{2+}$ and $\mathrm{Pb}^{2+}$ ions could be achieved using developed PQ-IIP $\mu$ PADs, and the performance of the $\mu$ PADs was further studied. The concentration of $\mathrm{Cd}^{2+}$ and $\mathrm{Pb}^{2+}$ ions was from 1 to $100 \mu \mathrm{g} / \mathrm{L}$. In order to detect the initial fluorescence intensity $F_{0}$ of the $\mu \mathrm{PADs}, 30 \mu \mathrm{L}$ ultrapure water was slowly added to the introducing area, when the sample flowed to the sensing sites, the fluorescence signal was measured. After air drying, $30 \mu \mathrm{L}$ sample solution containing different concentration of $\mathrm{Cd}^{2+}$ and $\mathrm{Pb}^{2+}$ ions were dropped to the introducing areas and detected the fluorescence intensity, respectively. It could be seen from Fig. 5A, as the concentration of $\mathrm{Cd}^{2+}$ ion increased, the fluorescence intensity of the PQ-Cd-IIP $\mu$ PADs showed a significant decline and excellent fluorescence quenching effect. The fluorescence intensity of PQ-Cd-IIP $\mu$ PADs provided a linear response from 1 to $70 \mu \mathrm{g} / \mathrm{L}$ with a lower detection limit of $0.245 \mu \mathrm{g} / \mathrm{L}$ (calculated using $3 \sigma /$ $\mathrm{s}$ criteria, where $\sigma$ is the slope of the linear calibration curve, and $\mathrm{s}$ is the standard deviation of corresponding ion's fluorescence intensity).The equation of linear regression was $y=0.0124 * c\left[\mathrm{Cd}^{2+}\right]+$ 0.0038 , with a correlation coefficient $\left(\mathrm{R}^{2}\right)$ of 0.996 . In addition, as shown in Fig. $5 \mathrm{~A}$ and B, Under the conditions of the same concentration of $\mathrm{Cd}^{2+}$ ions, the fluorescence quenching effect of the non-imprinted polymers PQ-NIP $\mu$ PADs was much smaller than PQ-Cd-IIP $\mu \mathrm{PADs}$, and the correlation coefficient $\left(\mathrm{R}^{2}\right)$ of PQ-NIP $\mu$ PADs was 0.974 . Similarly, as illustrated in Fig. 5C and D, when the concentration of $\mathrm{Pb}^{2+}$ ions was between 1 to $60 \mu \mathrm{g} / \mathrm{L}$, the fluorescence intensity of PQ$\mathrm{Pb}-\mathrm{IIP} \mu \mathrm{PADs}$ was linearly, the equation of linear regression was $y=0.0241^{*} c\left[\mathrm{~Pb}^{2+}\right]+0.0053$, with a correlation coefficient $\left(R^{2}\right)$ of 0.993 , and the limit of detection (LOD) was $0.335 \mu \mathrm{g} / \mathrm{L}$, and the correlation coefficient $\left(\mathrm{R}^{2}\right)$ of PQ-NIP $\mu$ PADs was 0.980 .

To verify the feasibility of fluorescence on-site detection using paper-based microfluidic chip, we set up the corresponding portable fluorometer device (as shown in Figs. S5 and S6) to cooperate with our chip with smartphone. However, this device is in the process of development and the smartphone's App was not finished, so we get the pictures by mobilephone and analyzed them by Image J analysis software. Briefly, the chip of PQ-Cd-IIP device was put into the bottom of the box and its fluorescence signal was excited by these LED lights and picture was captured by smartphone camera. The excited fluorescence images could be analyzed by ImageJ analysis software and the results showed good effect. The linear regression was $y=0.5067 x+91.069$, with a correlation coefficient $\left(\mathrm{R}^{2}\right)$ of 0.977 .

In order to demonstrate the stability and good uniformity of fluorescence intensity of PQ-IIP $\mu$ PADs, we tested the fluorescence intensity of 15 various locations on one PQ-Cd-IIP, and the RSD was $4.2 \%$ (as shown in Fig. S7). Then we stored six different PQ-Cd-IIP $\mu$ PADs in a dark environment at room temperature for 14 days and tested its original fluorescence intensity every day, the results were shown in Fig. S8. The fluorescence intensity almost keep no changed stable after 14 days restored, that indicated the $\mu \mathrm{PADs}$ had satisfactory reproducibility 

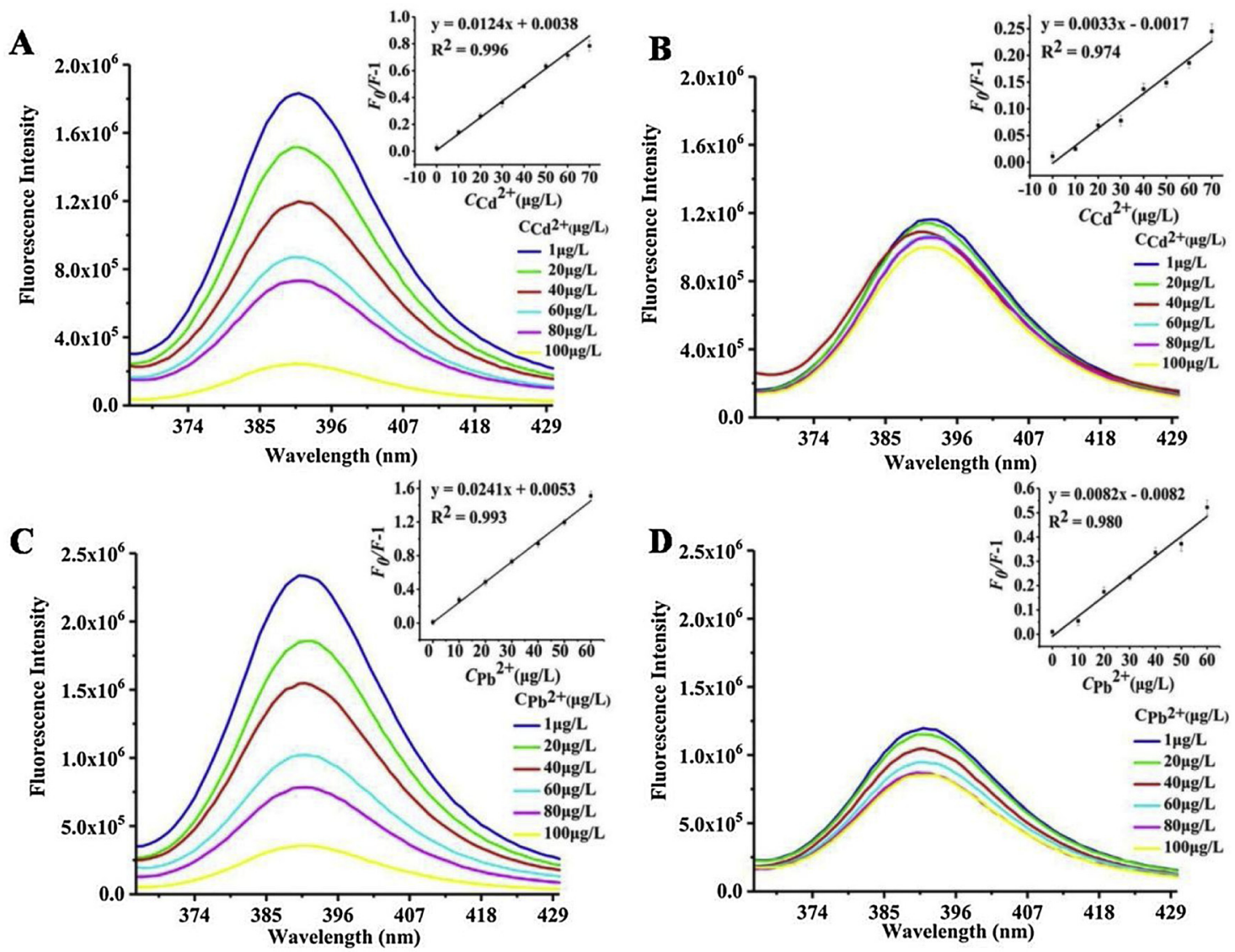

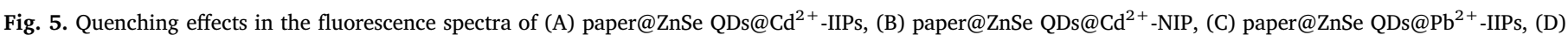
paper@ZnSe QDs@ $\mathrm{Pb}^{2+}$-NIP. The concentration of the $\mathrm{Cd}^{2+}$ and $\mathrm{Pb}^{2+}$ ions were from 1 to $100 \mu \mathrm{g} / \mathrm{L}$. The corresponding Stern-Volmer plot curves of the IIPs and NIP are shown in the insets. The experimental conditions were $\mathrm{pH} 7.0$ under room temperature; The excitation wavelength was $348 \mathrm{~nm}$, the slit widths of emission and excitation were $5 \mathrm{~nm}(\mathrm{n}=5)$.

and good storage stability.

In order to evaluate the specificity of the PQ-IIP $\mu$ PADs for $\mathrm{Cd}^{2+}$ and $\mathrm{Pb}^{2+}$ ions, $\mathrm{Co}^{2+}, \mathrm{Cu}^{2+}, \mathrm{Hg}^{2+}$ and $\mathrm{Ni}^{2+}$ ions were selected as the interference ions, which also cause slight quenching effects when directly contacted with ZnSe quantum dots. The concentration of $\mathrm{Cd}^{2+}$ and $\mathrm{Pb}^{2+}$ ions solution was selected as $40 \mu \mathrm{g} / \mathrm{L}$, other interference ions solution was $100 \mu \mathrm{g} / \mathrm{L}$, and the adsorption time was set to $15 \mathrm{~min}$, the results was shown in Fig. 6A and B. The fluorescence quenching effects of $\mathrm{Cd}^{2+}$ ion on the PQ-IIP $\mu$ PADs was most obvious (Fig. 6A), similarly, the fluorescence quenching effects of $\mathrm{Pb}^{2+}$ ion on the PQ-IIP $\mu$ PADs was most obvious (Fig. 6B), too. This phenomenon indicated that the ion imprinting layer had a specific recognition for the template ions, and the interference of other ions on the fluorescence performance of the quantum dots could be excluded by a specific recognition site. Although common heavy metal ions had slight quenching effects on fluorescence, it did not cause too much interference with the results of fluorescence quenching. Therefore, PQ-IIP $\mu$ PADs had a specific recognition for the template ion and could be used to detect actual samples.
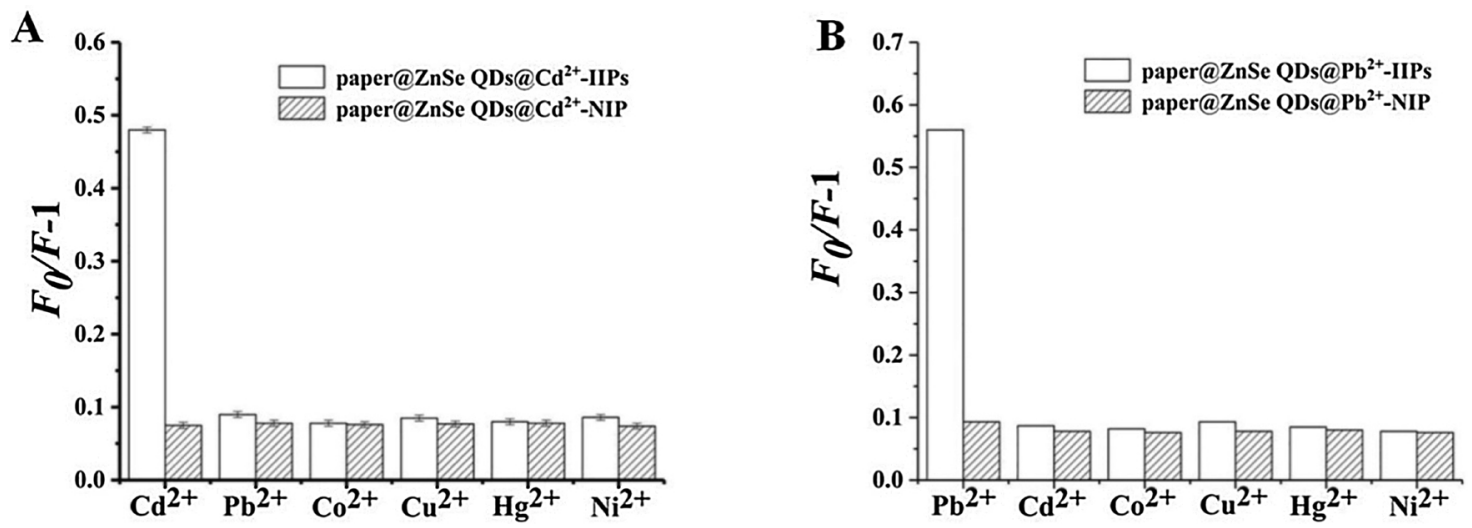

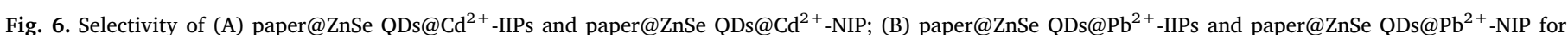
sample solutions of different interfering ions $\left(\mathrm{Cd}^{2+}, \mathrm{Pb}^{2+}, \mathrm{Co}^{2+}, \mathrm{Cu}^{2+}, \mathrm{Hg}^{2+}, \mathrm{Ni}^{2+}\right)$. The concentration of $\mathrm{Cd}^{2+}$ and $\mathrm{Pb}^{2+}$ ions was $40 \mu \mathrm{g} / \mathrm{L}$ and other interference ions solution was $100 \mu \mathrm{g} / \mathrm{L}(\mathrm{n}=5)$. 
Table 1

Recovery of $\mathrm{Cd}^{2+}$ and $\mathrm{Pb}^{2+}$ in Lake water and Seawater detected using paper@ ZnSe QDs@IIPs $\mu$ PADs $(\mathrm{n}=5)$.

\begin{tabular}{|c|c|c|c|c|c|c|}
\hline \multirow[t]{2}{*}{ Sample } & \multicolumn{2}{|l|}{ Added } & \multicolumn{2}{|c|}{ Founded } & \multicolumn{2}{|c|}{ Recovery \pm RSD } \\
\hline & $\begin{array}{l}\mathrm{Cd}^{2+} \\
(\mu \mathrm{g} / \mathrm{L})\end{array}$ & $\begin{array}{l}\mathrm{Pb}^{2+} \\
(\mu \mathrm{g} / \mathrm{L})\end{array}$ & $\begin{array}{l}\mathrm{Cd}^{2+} \\
(\mu \mathrm{g} / \mathrm{L})\end{array}$ & $\begin{array}{l}\mathrm{Pb}^{2+} \\
(\mu \mathrm{g} / \mathrm{L})\end{array}$ & $\mathrm{Cd}^{2+}(\%)$ & $\mathrm{Pb}^{2+}(\%)$ \\
\hline \multirow[t]{3}{*}{ Lake water } & 5 & 5 & 4.94 & 4.75 & $98.8 \pm 4.7$ & $95.0 \pm 4.3$ \\
\hline & 10 & 10 & 9.86 & 9.83 & $98.6 \pm 4.8$ & $98.3 \pm 3.1$ \\
\hline & 15 & 15 & 15.76 & 14.86 & $105.1 \pm 5.6$ & $99.1 \pm 3.2$ \\
\hline \multirow[t]{3}{*}{ Seawater } & 5 & 5 & 4.75 & 5.21 & $95.0 \pm 4.1$ & $104.2 \pm 4.3$ \\
\hline & 10 & 10 & 10.08 & 10.06 & $100.8 \pm 3.6$ & $100.6 \pm 3.1$ \\
\hline & 15 & 15 & 15.26 & 15.11 & $101.7 \pm 3.1$ & $100.7 \pm 3.2$ \\
\hline
\end{tabular}

3.7. Application of the paper@ZnSe QDs@IIPs $\mu$ PADs for $\mathrm{Cd}^{2+}$ and $\mathrm{Pb}^{2+}$ ions detection in real samples

To validate the actual application of the PQ-IIP $\mu$ PADs, we put $\mathrm{Cd}^{2+}$ ion imprinted fluorescence chip and $\mathrm{Pb}^{2+}$ ion imprinted fluorescence chip on the $\mu$ PADs to detect $\mathrm{Cd}^{2+}$ and $\mathrm{Pb}^{2+}$ ions simultaneously in the real samples. Seawater samples were obtained from fisherman's wharf of the Yellow Sea which located in Laishan District of Yantai City, and lake water samples were from Sanyuan Lake of Yantai University. The spiked concentration of $\mathrm{Cd}^{2+}$ and $\mathrm{Pb}^{2+}$ ions were $5 \mu \mathrm{g} / \mathrm{L}, 10 \mu \mathrm{g} / \mathrm{L}$, and $15 \mu \mathrm{g} / \mathrm{L}$, respectively. The results of the method were shown in Table 1 , the recovery rates of lake water and seawater were from 95.0\%-105.1\%, and RSDs ranged from 3.1\%-5.6\%. Furthermore, the designed $\mu$ PADs could realize the pretreatment process by its pre-filter function. To prove it, we added an additional experiment as shown in Fig. S9. It can be observed that in the sewage samples including sandy seawater and algae-rich lake water, some dirty pollutants can be well filtered out. The purpose using hydrophilic channel can easily solve the interference of dirty contaminants fluorescence signal using the direct dipping method.

\subsection{Comparison of various methods' performance}

As shown in Table S1, the results of PQ-IIP $\mu$ PADs for detecting $\mathrm{Cd}^{2+}$ and $\mathrm{Pb}^{2+}$ ions was prepared with previously reported literature. From the Table we could see that our PQ-IIP $\mu$ PADs exhibited high sensitivity and recognition for $\mathrm{Cd}^{2+}$ and $\mathrm{Pb}^{2+}$ ions, although the limit of detection of our method was slightly higher than some results reported previously, the synthesized ion-imprinted polymers had specific recognition sites that avoided interferences from other ions. According to the maximum level of drinking water standards of United States Environmental Protection Agency issued, the content of cadmium ion is lower than $5 \mu \mathrm{g} / \mathrm{L}$, and lead ion is lower than $15 \mu \mathrm{g} / \mathrm{L}$. The developed $\mu \mathrm{PAD}$ successfully quantified $0.245 \mu \mathrm{g} / \mathrm{L}$ of $\mathrm{Cd}$ and $0.335 \mu \mathrm{g} / \mathrm{L}$ of $\mathrm{Pb}$, both are lower than standards and can be used for the environmental water samples detection. In addition, the PQ-IIP $\mu$ PADs could recognize two ions at the same time, which was impossible for most other methods, reflected the PQ-IIP $\mu$ PADs equipment was both highly sensitive and efficient.

\section{Conclusions}

In this work, we developed a novel, versatile and portable platform for multi-channel detection of heavy metal $\mathrm{Cd}^{2+}$ and $\mathrm{Pb}^{2+}$ ions, using ZnSe QDs and ion imprinting technology. To the best our knowledge, this is the first time to use ZnSe QDs and ion imprinting technology on 3D rotary $\mu$ PADs platform to realize the multiplexed determination of heavy metal ions in a facile, simple and robust way. Compared to CdTe quantum dots, ZnSe quantum dots are less toxic and more environmentally friendly. Moreover, this method not only had good selectivity and sensitivity, but also demonstrated good repeatability in the process of detecting $\mathrm{Cd}^{2+}$ and $\mathrm{Pb}^{2+}$ ions in actual water samples. The developed sensor of $\mathrm{Cd}^{2+} \mu$ PADs provided a linear response from 1 to $70 \mu \mathrm{g} / \mathrm{L}$ with a lower detection limit of $0.245 \mu \mathrm{g} / \mathrm{L}$, and $\mathrm{Pb}^{2+} \mu$ PADs provided a linear response from 1-60 $\mu \mathrm{g} / \mathrm{L}$ with a lower detection limit of $0.335 \mu \mathrm{g} / \mathrm{L}$, and the real samples recovery rate was $95.0 \%-105.1 \%$, and RSDs ranged from $3.1 \%-5.6 \%$, respectively. The technique has various appealing benefits, including low cost, portability, and QD's environmentally friendly form, and we expected that the paper@ZnSe QDs@IIPs $\mu$ PADs platform would have broad application prospects in environmental pollution detection and food safety testing.

\section{Declaration of Competing Interest}

The authors declare that they have no known competing financial interests or personal relationships that could have appeared to influence the work reported in this paper.

\section{Acknowledgements}

This work was financially supported by the National Key Research and Development Program of China (Grant No. 2016YFC1400702), the National Natural Science Foundation of China (Grant No. 41776110), the Department of Science and Technology of Shandong Province of China (GG201709290055), the Science and Technology Development Plan of Yantai (2017ZH093), the Project Sponsored by the Scientific Research Foundation for the Returned Overseas Chinese Scholars, State Education Ministry, and Taishan Scholar Project Special Funding.

\section{Appendix A. Supplementary data}

Supplementary material related to this article can be found, in the online version, at doi:https://doi.org/10.1016/j.snb.2019.127462.

\section{References}

[1] X.M. Liu, Q.J. Song, Y. Tang, W.L. Li, J.M. Xu, J.J. Wu, F. Wang, P.C. Brookes, Human health risk assessment of heavy metals in soil-vegetable system: a multimedium analysis, Sci. Total Environ. 463 (2013) 530-540.

[2] Y.B. Man, X.L. Sun, Y.G. Zhao, B.N. Lopez, S.S. Chung, S.C. Wu, K.C. Cheung, M.H. Wong, Health risk assessment of abandoned agricultural soils based on heavy metal contents in Hong Kong, the world's most populated city, Environ. Int. 36 (2010) 570-576.

[3] L. Jarup, Cadmium overload and toxicity, Nephrol. Dial. Transplant. 17 (2002) 35-39.

[4] N. Johri, G. Jacquillet, R. Unwin, Heavy metal poisoning: the effects of cadmium on the kidney, Biometals 23 (2010) 783-792.

[5] K.R. Mahaffey, Relation between quantities of Lead ingestes and health effects of Lead in humans, Pediatrics 59 (1977) 448-456.

[6] J. Yan, E.M. Indra, Colorimetric method for determining $\mathrm{Pb}^{2+}$ ions in water enhanced with non-precious-metal Nanoparticles, Anal. Chem. 84 (2012) 6122-6127.

[7] W. Yun, D.Z. Cai, J.L. Jiang, P.X. Zhao, Y. Huang, G. Sang, Enzyme-free and labelfree ultra-sensitive colorimetric detection of $\mathrm{Pb}^{2+}$ using molecular beacon and DNAzyme based amplification strategy, Biosens. Bioelectron. 80 (2016) 187-193.

[8] H.N. Kim, W.X. Ren, J.S. Kim, J. Yoon, Fluorescent and colorimetric sensors for detection of lead, cadmium, and mercury ions, Chem. Soc. Rev. 41 (2012) 3210-3244.

[9] X.S. Zhu, C. Gao, J.W. Choi, P.L. Bishop, C.H. Ahn, On-chip generated mercury microelectrode for heavy metal ion detection, Lab Chip 5 (2005) 212-217.

[10] J. Ding, T. Cherubini, D. Yuan, E. Bakker, Paper-supported thin-layer ion transfer voltammetry for ion detection, Sens. Actuators B Chem. 280 (2019) 69-76.

[11] P.R.M. Silva, M.A. El Khakani, M. Chaker, A. Dufresne, F. Courchesne, Simultaneous determination of $\mathrm{Cd}, \mathrm{Pb}$, and $\mathrm{Cu}$ metal trace concentrations in water certified samples and soil extracts by means of Hg-electroplated-Ir microelectrode array based sensors, Sens. Actuators B Chem. 76 (2001) 250-257.

[12] G.M. Cockrell, G. Zhang, D.G. VanDerveer, R.P. Thummel, R.D. Hancock, Enhanced metal ion selectivity of 2,9-di-(pyrid-2-yl)-1,10-phenanthroline and its use as a fluorescent sensor for cadmium(II), J. Am. Chem. Soc. 130 (2008) 1420-1430.

[13] L.J. Zhang, X.Y. Huang, Y. Cao, Y.H. Xin, L.P. Ding, Fluorescent binary ensemble based on pyrene derivative and sodium dodecyl sulfate assemblies as a chemical tongue for discriminating metal ions and brand water, ACS Sens. 2 (2017) 1821-1830.

[14] T.Y. Cheng, T. Wang, W.P. Zhu, X.L. Chen, Y.J. Yang, Y.F. Xu, X.H. Qin, Redemission fluorescent probe sensing cadmium and pyrophosphate selectively in aqueous solution, Org. Lett. 13 (2011) 3656-3659.

[15] J. Yin, T. Wu, J.B. Song, Q. Zhang, S.Y. Liu, R. Xu, H.W. Duan, SERS-active 
nanoparticles for sensitive and selective detection of cadmium ion $\left(\mathrm{Cd}^{2+}\right)$, Chem. Mater. 23 (2011) 4756-4764.

[16] M. Cuartero, G.A. Crespo, E. Bakker, Paper-based thin-layer coulometric sensor for halide determination, Anal. Chem. 87 (2015) 1981-1990.

[17] A.W. Martinez, S.T. Phillips, G.M. Whitesides, Three-dimensional microfluidic devices fabricated in layered paper and tape, Proc. Natl. Acad. Sci. U. S. A. 105 (2008) 19606-19611.

[18] K. Tenda, B. van Gerven, R. Arts, Y. Hiruta, M. Merkx, D. Citterio, Paper-based antibody detection devices using bioluminescent BRET-Switching sensor proteins, Angew. Chemie Int. Ed. English 57 (2018) 15369-15373.

[19] K. Yamada, D. Citterio, C.S. Henry, "Dip-and-read" paper-based analytical devices using distance-based detection with color screening, Lab Chip 18 (2018) $1485-1493$.

[20] N.A. Meredith, C. Quinn, D.M. Cate, T.H. Reilly, J. Volckens, C.S. Henry, Paperbased analytical devices for environmental analysis, Analyst 141 (2016) 1874-1887.

[21] B.W. Li, L.J. Yu, J. Qi, L.W. Fu, P.Q. Zhang, L.X. Chen, Controlling capillary-driven fluid transport in paper-based microfluidic devices using a movable valve, Anal. Chem. 89 (2017) 5708-5713.

[22] J.L. Han, A.J. Qi, J.R. Zhou, G. Wang, B.W. Li, L.X. Chen, Simple way to fabricate novel paper-based valves using plastic comb binding spines, ACS Sens. 3 (2018) 1789-1794.

[23] K. Yamada, T.G. Henares, K. Suzuki, D. Citterio, Distance-based tear lactoferrin assay on microfluidic paper device using interfacial interactions on surface-modified cellulose, ACS Appl. Mater. Interfaces 7 (2015) 24864-24875.

[24] H. Liu, R.M. Crooks, Three-dimensional paper microfluidic devices assembled using the principles of origami, J. Am. Chem. Soc. 133 (2011) 17564-17566.

[25] S. Rengaraj, A. Cruz-Izquierdo, J.L. Scott, M. Di Lorenzo, Impedimetric paper-based biosensor for the detection of bacterial contamination in water, Sens. Actuators B Chem. 265 (2018) 50-58.

[26] J. Qi, B.W. Li, N. Zhou, X.Y. Wang, D.M. Deng, L.Q. Luo, L.X. Chen, The strategy of antibody-free biomarker analysis by in-situ synthesized molecularly imprinted polymers on movable valve paper-based device, Biosens. Bioelectron. 142 (2019).

[27] J.W. Ding, B.W. Li, L.X. Chen, W. Qin, A three-dimensional origami paper-based device for potentiometric biosensing, Angew. Chemie Int. Ed. English 55 (2016) 13033-13037.

[28] B.W. Li, W. Zhang, L.X. Chen, B.C. Lin, A fast and low-cost spray method for prototyping and depositing surface-enhanced Raman scattering arrays on microfluidic paper based device, Electrophoresis 34 (2013) 2162-2168.

[29] A. Saha, N.R. Jana, Paper-based microfluidic approach for surface-enhanced raman spectroscopy and highly reproducible detection of proteins beyond picomolar concentration, ACS Appl. Mater. Interfaces 7 (2015) 996-1003.

[30] Q.K. Kong, Y.H. Wang, L.N. Zhang, S.G. Ge, J.H. Yu, A novel microfluidic paperbased colorimetric sensor based on molecularly imprinted polymer membranes for highly selective and sensitive detection of bisphenol A, Sens. Actuators B Chem. 243 (2017) 130-136.

[31] B.W. Li, L.W. Fu, W. Zhang, W.W. Feng, L.X. Chen, Portable paper-based device for quantitative colorimetric assays relying on light reflectance principle, Electrophoresis 35 (2014) 1152-1159.

[32] K. Zhang, Q.S. Mei, G.J. Guan, B.H. Liu, S.H. Wang, Z.P. Zhang, Ligand replacement-induced fluorescence switch of quantum dots for ultrasensitive detection of organophosphorothioate pesticides, Anal. Chem. 82 (2010) 9579-9586.

[33] K.E. Sapsford, J. Granek, J.R. Deschamps, K. Boeneman, J.B. Blanco-Canosa, P.E. Dawson, K. Susumu, M.H. Stewart, I.L. Medintz, Monitoring botulinum neurotoxin a activity with peptide-functionalized quantum dot resonance energy transfer sensors, ACS Nano 5 (2011) 2687-2699.

[34] L. Feng, A. Zhu, H.C. Wang, H.C. Shi, A nanosensor based on quantum-dot haptens for rapid, on-site immunoassay of cyanotoxin in environmental water, Biosens. Bioelectron. 53 (2014) 1-4.

[35] X.X. Xu, D. Liu, L.J. Luo, L.B. Li, K. Wang, T.Y. You, Photoelectrochemical aptasensor based on CdTe quantum dots-single walled carbon nanohorns for the sensitive detection of streptomycin, Sens. Actuators B Chem. 251 (2017) 564-571.

[36] L. Wang, R. Yang, J.J. Li, L.B. Qu, P.D. Harrington, High-sensitive electrochemical sensor of Sudan I based on template-directed self-assembly of graphene-ZnSe quantum dots hybrid structure, Sens. Actuators B Chem. 215 (2015) 181-187.

[37] A. Wang, H.B. Shen, S.P. Zang, Q.L. Lin, H.Z. Wang, L. Qian, J.Z. Niu, L.S. Li, Bright, efficient, and color-stable violet ZnSe-based quantum dot light-emitting diodes, Nanoscale 7 (2015) 2951-2959.

[38] Z.X. Cai, B.Q. Shi, L. Zhao, M.H. Ma, Ultrasensitive and rapid lead sensing in water based on environmental friendly and high luminescent L-glutathione-capped-ZnSe quantum dots, Spectrochim. Acta A. 97 (2012) 909-914.

[39] B.W. Li, Z. Zhang, J. Qi, N. Zhou, S. Qin, J. Choo, L.X. Chen, Quantum dot-based molecularly imprinted polymers on three-dimensional origami paper microfluidic chip for fluorescence detection of Phycocyanin, ACS Sens. 2 (2017) 243-250.

[40] J. Qi, B.W. Li, X.Y. Wang, L.W. Fu, L.Q. Luo, L.X. Chen, Rotational paper-based microfluidic-chip device for multiplexed and simultaneous fluorescence detection of phenolic pollutants based on a molecular-imprinting technique, Anal. Chem. 90 (2018) 11827-11834.

[41] J.Q. Fu, L.X. Chen, J.H. Li, Z. Zhang, Current status and challenges of ion imprinting, J. Mater. Chem. A Mater. Energy Sustain. 3 (2015) 13598-13627.

[42] T.P. Rao, R. Kala, S. Daniel, Metal ion-imprinted polymers - Novel materials for selective recognition of inorganics, Anal. Chim. Acta 578 (2006) 105-116.

[43] L.X. Chen, S.F. Xu, J.H. Li, Recent advances in molecular imprinting technology: current status, challenges and highlighted applications, Chem. Soc. Rev. 40 (2011) 2922-2942.

[44] F. Zhu, L.W. Li, J.D. Xing, Selective adsorption behavior of Cd(II) ion imprinted polymers synthesized by microwave-assisted inverse emulsion polymerization: adsorption performance and mechanism, J. Hazard. Mater. 321 (2017) 103-110.

[45] A. Baghel, M. Boopathi, B. Singh, P. Pandey, T.H. Mahato, P.K. Gutch, K. Sekhar, Synthesis and characterization of metal ion imprinted nano-porous polymer for the selective recognition of copper, Biosens. Bioelectron. 22 (2007) 3326-3334.

[46] V. Vatanpour, S.S. Madaeni, S. Zinadini, H.R. Rajabi, Development of ion imprinted technique for designing nickel ion selective membrane, J. Membr. Sci. 373 (2011) $36-42$.

[47] J. Qi, B.W. Li, X.R. Wang, Z. Zhang, Z. Wang, J.L. Han, L.X. Chen, Three-dimensional paper-based microfluidic chip device for multiplexed fluorescence detection of $\mathrm{Cu}^{2+}$ and $\mathrm{Hg}^{2+}$ ions based on ion imprinting technology, Sens. Actuators B Chem. 251 (2017) 224-233.

[48] V.V. Nikesh, S. Mahamuni, Highly photoluminescent ZnSe/ZnS quantum dots, Semicond. Sci. Technol. 16 (2001) 687-690.

[49] S.F. Xu, H.Z. Lu, J.H. Li, X.L. Song, A.X. Wang, L.X. Chen, S.B. Han, Dummy molecularly imprinted polymers-capped CdTe quantum dots for the fluorescent sensing of 2,4,6-Trinitrotoluene, ACS Appl. Mater. Interfaces 5 (2013) 8146-8154.

[50] X.Q. Wu, Z. Zhang, J.H. Li, H.Y. You, Y.B. Li, L.X. Chen, Molecularly imprinted polymers-coated gold nanoclusters for fluorescent detection of bisphenol A, Sens. Actuators B Chem. 211 (2015) 507-514.

Junrui Zhou is a postgraduate at School of Environment and Materials Engineering, Yantai University and the Yantai Institute of Coastal Zone Research, Chinese Academy of Sciences. His current research interests are the combination of molecular imprinting technology and paper-based microfluidic technology for the detection of environment pollutions.

Bowei Li is currently as an associate professor at Yantai Institute of Coastal Zone Research, Chinese Academy of Sciences. He received his $\mathrm{PhD}$ at Dalian Institute of Chemical Physics, Chinese Academy of Sciences, in 2009. During 2009-2011, he worked at Department of Chemistry, Florida State University as a postdoctoral fellow. In 2011, he joined in Yantai Institute of Coastal Zone Research, Chinese Academy of Sciences. His research interests focus on the environmental monitoring, point-of-care testing, and other fields of basic research on chemical and biological using microfluidic chip platform.

Anjin Qi is a postgraduate at School of Environment and Materials Engineering, Yantai University and the Yantai Institute of Coastal Zone Research, Chinese Academy of Sciences. She is dedicated to the study of microcystins on three-dimensional microfluidic paper chips by molecular imprinting.

Yajun Shi is currently as a senior engineer at Yantai Institute of Coastal Zone Research, Chinese Academy of Sciences. He received his $\mathrm{PhD}$ in environmental science from Graduate University of the Chinese Academy of Sciences, Beijing,China, in 2011. In the same year, he joined in Yantai Institute of Coastal Zone Research, Chinese Academy of Sciences, as an assistant professor. In 2017, he became a senior engineer. His current research interest focuses on marine ecology.

Ji Qi is currently a $\mathrm{PhD}$ degree candidate, under the guidance of Prof. Liqiang Luo and Prof. Lingxin Chen, at College of Sciences, Shanghai University, China, since 2017. He received his master degree, under the guidance of Prof. Lingxin Chen and Prof. Zhuo Wang, at School of Environment and Materials Engineering, Yantai University and Yantai Institute of Coastal Zone Research, Chinese Academy of Sciences, since 2015. His current research interests are the using imprinting materials to make investigations on the paperbased microfluidic devices.

Huizhong Xu is currently as a professor at Environment and Material Engineering School of Yantai University, Shandong, China. He obtained his master degree in geology from Hefei University of Technology, Hefei, Anhui, China, and his PhD degree in material science from Harbin Institute of Technology, Harbin, Heilongjiang, China, in 2011. His research interests include the studies of ecological materials and environment monitoring equipment such as restoration materials for destroyed land, on-line automatic analyzer for water quality.

Lingxin Chen is currently as a professor at Yantai Institute of Coastal Zone Research, Chinese Academy of Sciences. He received his $\mathrm{PhD}$ degree in analytical chemistry from the Dalian Institute of Chemical Physics, Chinese Academy of Sciences, Dalian, in 2003. After 2 years of postdoctoral experience at the Department of Chemistry, Tsinghua University, Beijing, he joined first as a BK21 researcher and then as a research professor at the Department of Applied Chemistry, Hanyang University, Korea, in 2006. In 2009, as a professor, he joined the Yantai Institute of Coastal Zone Research, Chinese Academy of Sciences, Yantai. His research interests include the studies of novel properties of materials such as functionalized nanoparticles for developing nanoscale biochemical analysis methods and molecular imprinting-based sample pretreatment technology. 